Journal of the Electrochemical Society, 1993, Volume 140, Issue 9, Pages 2507-2511.

ISSN: $0013-4651$

DOI: $10.1149 / 1.2220852$

http://www.electrochem.org/

http://scitation.aip.org/getpdf/servlet/GetPDFServlet?filetype=pdf\&id=JESOAN000140000009002507000001\&idty pe $=$ cvips\&prog $=$ normal

(C) The Electrochemical Society, Inc. 1993. All rights reserved. Except as provided under U.S. copyright law, this work may not be reproduced, resold, distributed, or modified without the express permission of The Electrochemical Society (ECS). The archival version of this work was published in Journal of the Electrochemical Society, 1993, Volume 140, Issue 9, Pages 2507-2511.

\title{
Corrosion Inhibition of Cobalt with a Thin Film of Cu-BTA
}

\author{
V. Brusic,* G. S. Frankel,* A. G. Schrott and T. A. Petersen \\ IBM Research Division, Thomas J. Watson Research Center, Yorktown Heights, New York.
}

\author{
B. M. Rush \\ Department of Chemical Engineering, University of California, Berkeley, Berkeley, California. \\ * Electrochemical Society Active Member.
}

\begin{abstract}
Electrochemical techniques, ellipsometry and $\mathrm{x}$-ray photoelectron spectroscopy were used to evaluate the use of benzotriazole, alone or in combination with boric acid/borate buffer and dilute copper sulfate for the protection of cobalt. The data indicate that in slightly alkaline solutions benzotriazole is a strong inhibitor for cobalt corrosion, whereas in water and neutral solutions it produces a barely measurable effect. In the presence of benzotriazole and $\mathrm{Cu}^{+2}$ ions, spontaneous reduction of copper ions leads to the formation of a thin film of Cu-BTA on the cobalt surface. This film acts as a corrosion protector that is better than benzotriazole, with a significant reduction of the corrosion rate even during subsequent exposure to solutions without inhibitors.
\end{abstract}

Corrosion is a spontaneous process and a ubiquitous problem for all but a few noble metals and metals that form a passivating oxide layer. Cobalt does not belong to either of these two groups. It is less noble than some other magnetic metals, such as nickel, and cobalt oxide is less passivating than nickel oxide on Ni. Due to their magnetic properties, Co and its alloys are widely used in thin film magnetic disks and heads. These thin film structures are particularly sensitive to corrosion loss, both during fabrication and in the field.

For magnetic recording applications, any passivation scheme that degrades the magnetic properties of the Co alloy is not viable. Alloying with metals such as $\mathrm{Cr}$, thermal oxidation and application of conversion layers are all problematic. Corrosion could be reduced in a fabrication step during which Co or a Co alloy is in contact with a process solution by the use of inhibitors. However, many of the recommended corrosion inhibitors for Co offer only limited protection in situ, and even less once the part is removed from the solution containing the inhibitor.

Copper is more noble than cobalt, and copper oxides, like cobalt oxide, are marginal surface passivators. Much of the usefulness of $\mathrm{Cu}$ results from the very successful inhibiting action of benzotriazole ( $1 \mathrm{H}$-BTA to be referred to here simply as BTA) and its derivatives. ${ }^{1}$ This compound reacts with $\mathrm{Cu}$ to form a $\mathrm{Cu}$-BTA surface film, which, depending on the details of preparation, might be only $2 \mathrm{~nm}$ thick but very protective. Once formed, the film reduces the corrosion rate of $\mathrm{Cu}$ in water (with or without BTA) by more than two orders of magnitude. ${ }^{2}$ This work describes the use of BTA, alone or in combination with other compounds such as 
boric acid/borate buffer and dilute $\mathrm{CuSO}_{4}$, for the protection of cobalt. The intention of the work is to evaluate if the spontaneous reduction of $\mathrm{Cu}^{+2}$ ions could lead to the formation of $\mathrm{Cu}$ (I)-BTA on Co. In order to be practical, the overall protection scheme should be such that the inhibiting solution itself is not aggressive and the treatment results in some lasting protection.

\section{Experimental}

The samples were $150 \mathrm{~nm}$ thick sputter-deposited films of cobalt. The corrosion inhibiting electrolytes were prepared as aqueous solutions with $\mathrm{pH}$ ranging from 6 to 9 , using various combinations of boric acid/borate buffer (BAB in Table I), ammonia, $0.01 M \mathrm{BTA}$, and $\mathrm{CuSO}_{4}$ of concentration varying from $10^{-5}$ to $10^{-3} \mathrm{M}$. The buffer used in most experiments contained $0.09 \mathrm{M}$ boric acid and $0.005 \mathrm{M}$ sodium borate, which had a $\mathrm{pH}$ of 8.2.

The samples were typically exposed to the inhibiting solution for 10 min by simple immersion. They were then dried with $\mathrm{N}_{2}$ and tested for their corrosion resistance. The effectiveness of the treatment was evaluated by electrochemical measurements in a droplet of distilled water, using a miniature electrochemical cell described elsewhere. ${ }^{3}$ Some of the measurements were conducted in an air-tight cell, made from Kel-F (3M, St. Paul, Minnesota) with quartz windows allowing for a simultaneous ellipsometric characterization of the sample surface.

In a typical electrochemical measurement (with or without an inhibitor), the open-circuit potential was measured during the first 10-15 min of the sample-electrolyte contact. The potential measurement was interrupted by a brief polarization resistance test after 1 and $5 \mathrm{~min}$ in solution. At the 10 min mark, a potentiodynamic polarization curve was initiated at a potential $250 \mathrm{mV}$ below the open-circuit value. The potential sweep rate was $1 \mathrm{mV} / \mathrm{s}$. Electrochemical potentials were measured and are reported against a mercurous sulfate electrode (MSE).

Samples were also characterized by ellipsometry and by $\mathrm{x}$-ray photoelectron spectroscopy (XPS) to assess the growth, thickness, and chemical composition of surface layers. Samples were rinsed, dried, and exposed to air prior to being introduced into the XPS chamber.

\section{Results and Discussion}

Cobalt in $\mathrm{CuSO}_{4}$-containing solutions.-The open-circuit potential of $\mathrm{Co}$ in water is normally more than $400 \mathrm{mV}$ below that of $\mathrm{Cu}$. The results are given in column 3 of Table 1, together with other data obtained in electrochemical tests in droplets of various electrolytes. 
Table I. Corrosion potential and rate measured on sputtered $\mathrm{Cu}$ and $\mathrm{Co}$ films in a droplet of solution.

\begin{tabular}{|c|c|c|c|}
\hline Solution & $\begin{array}{l}\text { Time } \\
(\min )\end{array}$ & $\begin{array}{c}V_{\text {corr }} \\
(\mathrm{mV}, \mathrm{MSE})\end{array}$ & $\begin{array}{c}I_{\text {corr }} \\
\left(\mathrm{A} / \mathrm{cm}^{2}\right)\end{array}$ \\
\hline $\begin{array}{l}\mathrm{Cu} \text { in water } \\
\text { triple distilled } \\
\mathrm{H}_{2} \mathrm{O}\end{array}$ & $\begin{array}{r}1 \\
5 \\
10\end{array}$ & $\begin{array}{c}-310 \\
-369 \\
-365 /-375\end{array}$ & $\begin{aligned} 7.8 & \times 10^{-6} \\
5.8 & \times 10^{-6} \\
6 & \times 10^{-6}\end{aligned}$ \\
\hline $\begin{array}{l}\text { Co in different ele } \\
\text { triple distilled } \\
\mathrm{H}_{2} \mathrm{O}\end{array}$ & $\begin{array}{r}\text { tes } \\
1 \\
5 \\
10\end{array}$ & $\begin{array}{c}-654 \\
-760 \\
-772 /-813\end{array}$ & $\begin{array}{r}2.3 \times 10^{-6} \\
9.1 \times 10^{-6} \\
1 \times 10^{-5}\end{array}$ \\
\hline $\begin{array}{l}\text { Boric acid } \\
\text { Borate (BAB) } \\
\text { pH } 8\end{array}$ & $\begin{array}{r}1 \\
5 \\
10\end{array}$ & $\begin{array}{c}-784 \\
-834 \\
-852 /-877\end{array}$ & $\begin{array}{r}5.4 \times 10^{-6} \\
6.9 \times 10^{-6} \\
1 \times 10^{-5}\end{array}$ \\
\hline $\mathrm{H}_{2} \mathrm{O} / \mathrm{BTA}$ & $\begin{array}{r}1 \\
5 \\
10\end{array}$ & $\begin{array}{c}-782 \\
-768 \\
-762 /-697\end{array}$ & $\begin{array}{r}1.1 \times 10^{-6} \\
3.9 \times 10^{-7} \\
1 \times 10^{-7}\end{array}$ \\
\hline $\begin{array}{l}\text { BAB } \\
\text { BTA } \\
\text { pH } 8\end{array}$ & $\begin{array}{r}1 \\
5 \\
10\end{array}$ & $\begin{array}{c}-590 \\
-634 \\
-630 /-822\end{array}$ & $\begin{array}{l}\simeq 3 \times 10^{-8} \\
\simeq 3 \times 10^{-8} \\
\simeq 1 \times 10^{-8}\end{array}$ \\
\hline $\begin{array}{l}10^{-3} M \mathrm{CuSO}_{4} \\
10^{-2} M \mathrm{BTA}\end{array}$ & $\begin{array}{r}1 \\
5 \\
10\end{array}$ & $\begin{array}{c}-776 \\
-784 \\
-786 /-729\end{array}$ & $\begin{aligned} 7.8 & \times 10^{-6} \\
2 & \times 10^{-6} \\
3 & \times 10^{-7}\end{aligned}$ \\
\hline $\begin{array}{l}10^{-4} M \mathrm{CuSO}_{4} \\
10^{-2} M \mathrm{BTA}\end{array}$ & $\begin{array}{r}1 \\
5 \\
10\end{array}$ & $\begin{array}{c}-792 \\
-794 \\
-792 /-732\end{array}$ & $\begin{aligned} 2.3 & \times 10^{-6} \\
1 & \times 10^{-6} \\
7.3 & \times 10^{-8}\end{aligned}$ \\
\hline $\begin{array}{l}10^{-5} M \mathrm{CuSO}_{4}^{\prime} \\
10^{-2} \mathrm{M} \mathrm{BTA}\end{array}$ & $\begin{array}{r}1 \\
5 \\
10\end{array}$ & $\begin{array}{c}-780 \\
-772 \\
-774 /-719\end{array}$ & $\begin{array}{r}1.3 \times 10^{-6} \\
4.3 \times 10^{-7} \\
5 \times 10^{-8}\end{array}$ \\
\hline $\begin{array}{l}\mathrm{BAB}, \mathrm{pH} 8 \\
10^{-4} \mathrm{M} \mathrm{CuSO}_{4} \\
10^{-2} \mathrm{BTA}\end{array}$ & $\begin{array}{r}1 \\
5 \\
9 \\
10\end{array}$ & $\begin{array}{c}-784 \\
-796 \\
-770 \\
-762 /-879\end{array}$ & $\begin{array}{r}2 \times 10^{-7} \\
4.9 \times 10^{-8} \\
3.7 \times 10^{-8} \\
\simeq 10^{-8}\end{array}$ \\
\hline $\begin{array}{l}\mathrm{BAB}, \mathrm{pH} 8 \\
10^{-5} \mathrm{CuSO}_{4} \\
10^{-2} \mathrm{BTA}^{-}\end{array}$ & $\begin{array}{r}1 \\
4 \\
8 \\
10\end{array}$ & $\begin{array}{c}-738 \\
-778 \\
-770 \\
-764 /-873\end{array}$ & $\begin{array}{r}3 \times 10^{-7} \\
6.6 \times 10^{-8} \\
2.4 \times 10^{-8} \\
<10^{-8}\end{array}$ \\
\hline $\begin{array}{l}\text { dil } \mathrm{NH}_{3} \\
10^{-5} \mathrm{CuSO}_{4} \\
10^{-2} \mathrm{BTA} \\
\text { pH } 9\end{array}$ & $\begin{array}{r}1 \\
5 \\
8 \\
10\end{array}$ & $\begin{array}{c}602 \\
-575 \\
-790 \\
-592 /-606\end{array}$ & $\begin{array}{r}4.7 \times 10^{-8} \\
7 \times 10^{-8} \\
7 \times 10^{-8} \\
8 \times 10^{-8}\end{array}$ \\
\hline
\end{tabular}




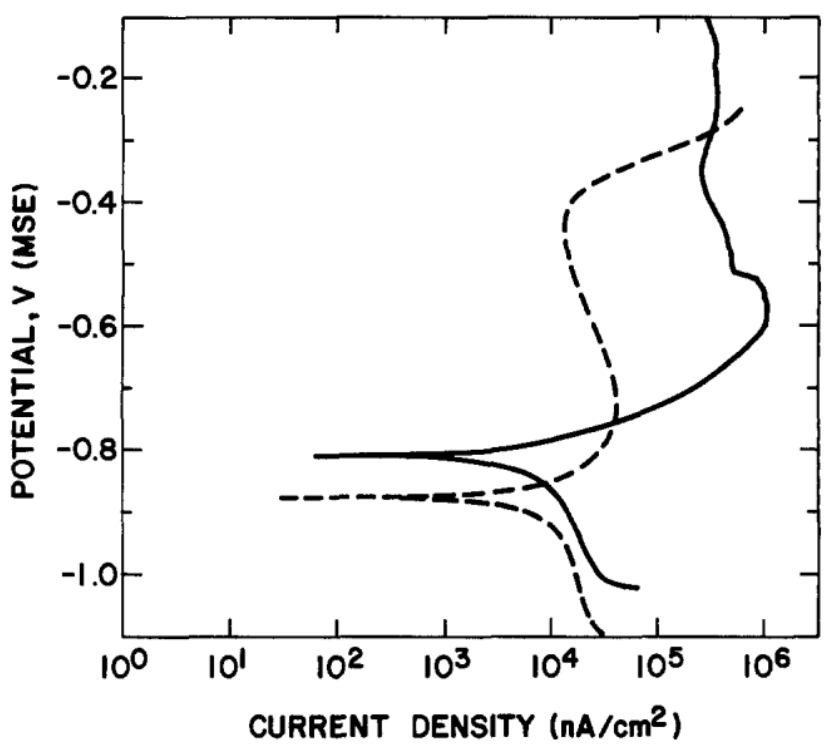

Fig. 1. Potentiodynamic polarization data obtained on Co in water (solid curve) and in boric acid/borate buffer (dashed curve).

At such low potentials the reduction of cupric ions should occur spontaneously. Given the low cupric concentrations used, the rate of reduction should be diffusion limited. The first step of cupric ion reduction is the formation of $\mathrm{Cu}^{+1}$. ${ }^{4}$ The hope was that cuprous ions would quickly react with the BTA-ions to form a thin protective $\mathrm{Cu}$-BTA film. However, the reduction of cupric ions is accompanied by the oxidation of Co metal. In case where the loss of Co (from corrosion or from a corrosion protection treatment) has to be small, it is important to keep the cupric ion concentration low. If, for example, the protective layer is to be formed in water (with additives), the safe limit of cupric ion concentration can be easily determined. Potentiodynamic polarization of $\mathrm{Co}$ in water, Fig. 1, indicates that the primary cathodic reaction is oxygen reduction. This reaction exhibits a diffusion controlled rate of approximately $1 \times 10^{-5} \mathrm{~A} / \mathrm{cm}^{2}$. The cupric concentration resulting in an equivalent diffusion-limited reduction current is $5.2 \times 10^{-4} \mathrm{M}$. For cupric concentrations below that value, the overall cathodic rate should be primarily oxygen reduction. For example, the partial cathodic current from cupric reduction in a solution containing $10^{-5} \mathrm{M}$ cupric ions should be more than an order of magnitude lower and unnoticeable in the measured current-potential curves.

Co passivation in slightly alkaline solutions. - When Co that is covered with a native oxide is placed into water or slightly alkaline solutions, it exhibits an open-circuit potential that decreases and a corrosion rate that increases with time. Results are listed in Table I. (Corrosion rates at 1 and $5 \mathrm{~min}$ were obtained from the polarization resistance measurements; the results after $10 \mathrm{~min}$ were obtained from the potentiodynamic polarization curves, with two potential values listed. The first is the open-circuit potential prior to the potentiodynamic sweep, and the second is the corrosion potential during the sweep. The fact that the two values are not identical indicates that this measurement disturbs the system to some extent. The measurements, however were conducted in a regimented manner, and the results can be used for a comparative evaluation of Co behavior in different electrolytes.) Such a change could indicate a slow dissolution of surface 
films. Ellipsometric data indicate that, in these electrolytes, the ellipsometric parameters $\Delta$ and $\psi$ increase with time at open circuit, supporting oxide removal. Figure 2 shows an example of the recorded changes of $\Delta$ and $\psi$ solution of $\mathrm{pH} 7.8$ during $27 \mathrm{~min}$ at the open-circuit potential followed by a reduction at $-1.2 \mathrm{~V}$ MSE. The total change of $\Delta$ is $+5.5^{\circ}$ (and of $\psi+0.56^{\circ}$ ), corresponding to a removal of about $2.6 \mathrm{~nm}$ of native oxide (using a best-fit refractive index $n \simeq$ $2.4-0.3 \mathrm{i}$ ). However, in the first $10 \mathrm{~min}$ in solution, the native oxide is barely removed, with $d \Delta=1.3^{\circ}$ or a removed thickness of less than $0.7 \mathrm{~nm}$. (These results are not fully reproducible from sample to sample; in many experiments the change of the optical parameters was smaller. However, the general trend was always the same.) Thus, although it is present on the surface, the native Co oxide is neither stable nor particularly protective against corrosion. In alkaline solutions, particularly those containing boric acid/borate buffer, polarization curves indicate the onset of passivation, Fig. 1 (see also Ref. 3). However, at the corrosion potential the corrosion rate in all cases is about $5-10 \times 10^{-6} \mathrm{~A} / \mathrm{cm}^{2}$, i.e., about as high as that measured in water.

Effect of BTA.- Significant inhibition of cobalt corrosion by BTA has not been reported in the literature. This may be because BTA reduces Co dissolution in water by a factor of only up to $\cong 10$ times (Table I, rows 2 and 4) which is significantly lower than the effect that is measured on $\mathrm{Cu}$. The effect of BTA is very reproducible and measurable even after the first minute in the solution, as the corrosion current decreases with time. After a $10 \mathrm{~min}$ exposure of Co to an aqueous solution containing BTA, there is a thin BTA film remaining on the surface which reduces the corrosion by a factor of $\leq 5$ times in water that does not contain BTA. However, in slightly alkaline solutions (i.e., in boric acid/ borate buffer or dilute ammonia), BTA reduces Co dissolution by almost 1000 times, Fig. 3. Subsequent corrosion in water (without BTA) is reduced by 4-10 times, Table II. Thus, in the presence of BTA, a small increase of solution $\mathrm{pH}$ results in an extraordinarily large reduction in corrosion rate. However, following the treatment with BTA, the behavior of Co in water is similar in both cases. Ellipsometric measurements of the residual films indicate that they are equally thin, with A decreasing by $<0.5^{\circ}$ and no change in $\psi$. Assuming a refractive index of $1.5,{ }^{2}$ this corresponds to a thickness of about $0.5 \mathrm{~nm}$ which is approximately one monolayer. BTA apparently adsorbs on the surface. The fact that $\Delta$ does not increase indicates that BTA prevents dissolution of the native oxide (which was described above for solutions devoid of BTA). The BTA film thickness formed in distilled water and in the buffer is about the same. Thus the drastic difference in corrosion rate must result from some other factor. 

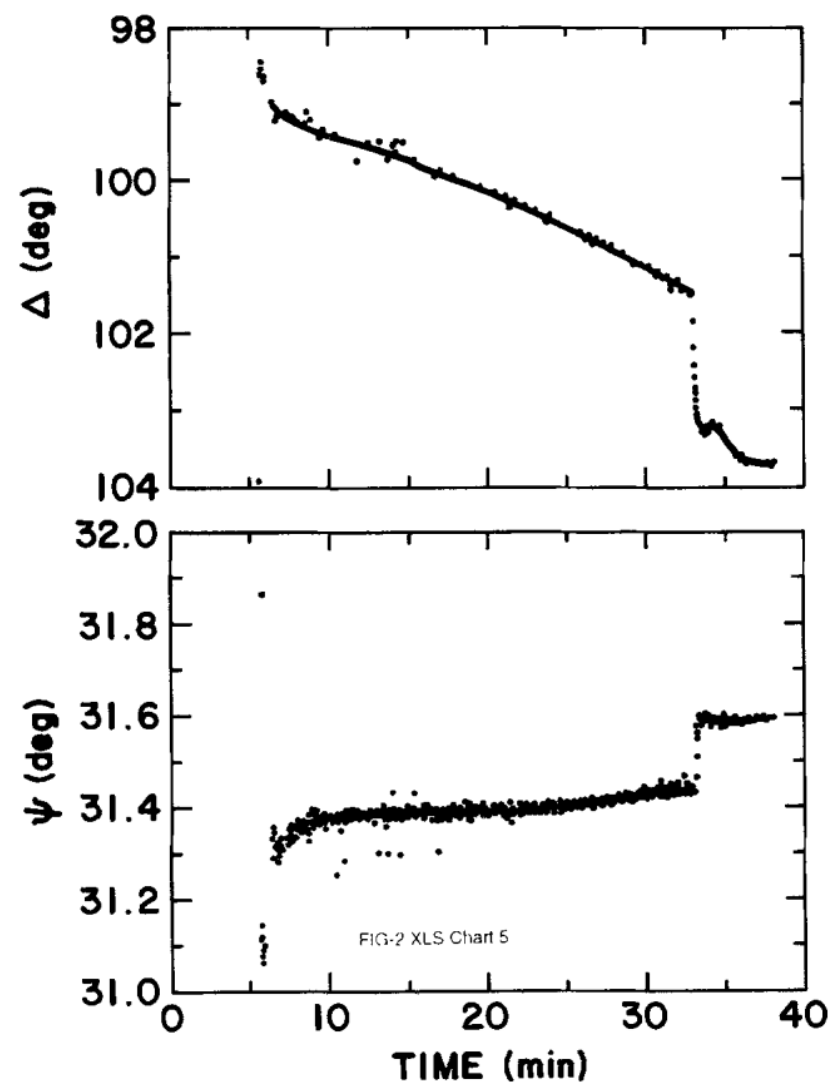

Fig. 2 The change of ellipsometric parameters $A$ and $V$ recorded in situ at the open-circuit potential followed by a reduction at $-1.6 \mathrm{~V}$ (at 36 min time) in a solution of $\mathrm{pH} 7.8$.

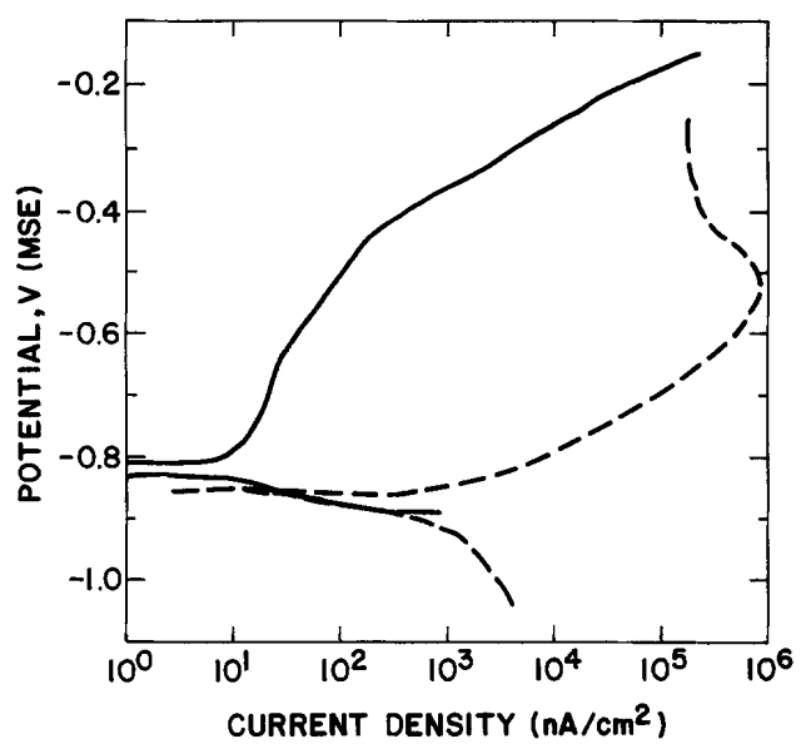

Fig. 3 Potentiodynamic polarization results obtained on $\mathrm{Co}$ in water (dashed line) and in boric acid/borate buffer (solid line) both with $10^{-2} M$ BTA. 
XPS evaluation of Co surface treated with BTA. $-\mathrm{N}$ is detected by XPS on the surfaces of Co samples following exposure to BTA-containing solutions. This proves that BTA is present in some form on the surface. The preparation steps after the solution exposure were identical in all cases, thus it may be assumed that any differences in the spectra can be attributed to influences of the electrolyte. Figure 4 shows the Co $2 p$ photoelectron spectra obtained on Co samples following immersion in different electrolytes. Curves a and $\mathrm{b}$ were obtained on samples immersed for 10 min in $\mathrm{H}_{2} \mathrm{O}$ and borate, respectively. Curves $\mathrm{c}$ and d correspond to immersion in the same two electrolytes, but with added BTA. The spectra only show the Co signal arising from the oxide film because the metallic contributions were subtracted to underscore the differences in the Co chemical environment of the oxide films. The intensity ratio of Co oxide to Co metallic in the measured spectra (not shown here) indicated an oxide film thickness of $3 \mathrm{~nm}$ for the sample immersed in $\mathrm{H}_{2} \mathrm{O}$ and $2.3 \mathrm{~nm}$ for the sample immersed in borate. Curve $\mathrm{b}$ differs from a in the height of the satellite located about $5 \mathrm{eV}$ from the main peak at $-780 \mathrm{eV}$. Comparison with reported XPS results on Co compounds ${ }^{5}$ indicates that curve a corresponds to a mixture of $\mathrm{CoO}$ and $\mathrm{CoO}(\mathrm{OH})$ and that curve b corresponds basically to $\mathrm{CoO}$. In contrast, curves $\mathrm{c}$ and $\mathrm{d}$ (measured after exposure to BTA-containing water and borate, respectively) resemble one another.

Table II. Corrosion potential and rate measured in a droplet of triple-distilled water on sputtered Co film after 10 min immersion in a BTA or $\mathrm{CuSO}_{4} / \mathrm{BTA}$ containing solution.

\begin{tabular}{|c|c|c|c|}
\hline Solution & $\begin{array}{l}\text { Time } \\
(\min )\end{array}$ & $\begin{array}{c}V_{\text {sort }} \\
(\mathrm{mV}, \mathrm{MSE})\end{array}$ & $\begin{array}{c}I_{\text {corr }} \\
\left(\mathrm{A} / \mathrm{cm}^{2}\right)\end{array}$ \\
\hline $\begin{array}{l}\text { BAB/BTA } \\
\text { pH } 8\end{array}$ & $\begin{array}{r}1 \\
5 \\
10\end{array}$ & $\begin{array}{c}-854 \\
-864 \\
-868 /-840\end{array}$ & $\begin{array}{r}8.1 \times 10^{-7} \\
8.3 \times 10^{-7} \\
\simeq 10^{-6}\end{array}$ \\
\hline $\begin{array}{l}\mathrm{BAB} \\
10^{-4} \mathrm{CuSO}_{4} \\
10^{-2} \mathrm{BTA}^{-}\end{array}$ & $\begin{array}{r}1 \\
5 \\
10\end{array}$ & $\begin{array}{c}-840 \\
-848 \\
-806 /-745\end{array}$ & $\begin{aligned} 2.7 & \times 10^{-7} \\
2.3 & \times 10^{-7} \\
3 & \times 10^{-7} \text { or } \\
1 & \times 10^{-6}\left(\mathrm{O}_{2} \text { diffusion }\right)\end{aligned}$ \\
\hline $\begin{array}{l}\mathrm{BAB} \\
10^{-5} \mathrm{CuSO}_{4} \\
10^{-2} \mathrm{BTA}^{\mathrm{BTA}}\end{array}$ & $\begin{array}{l}1 \\
5 \\
9\end{array}$ & $\begin{array}{c}-816 \\
-786 \\
-704 /-745\end{array}$ & $\begin{array}{r}2.4 \times 10^{-8} \\
1.8 \times 10^{-8} \\
2 \times 10^{-7}\end{array}$ \\
\hline
\end{tabular}




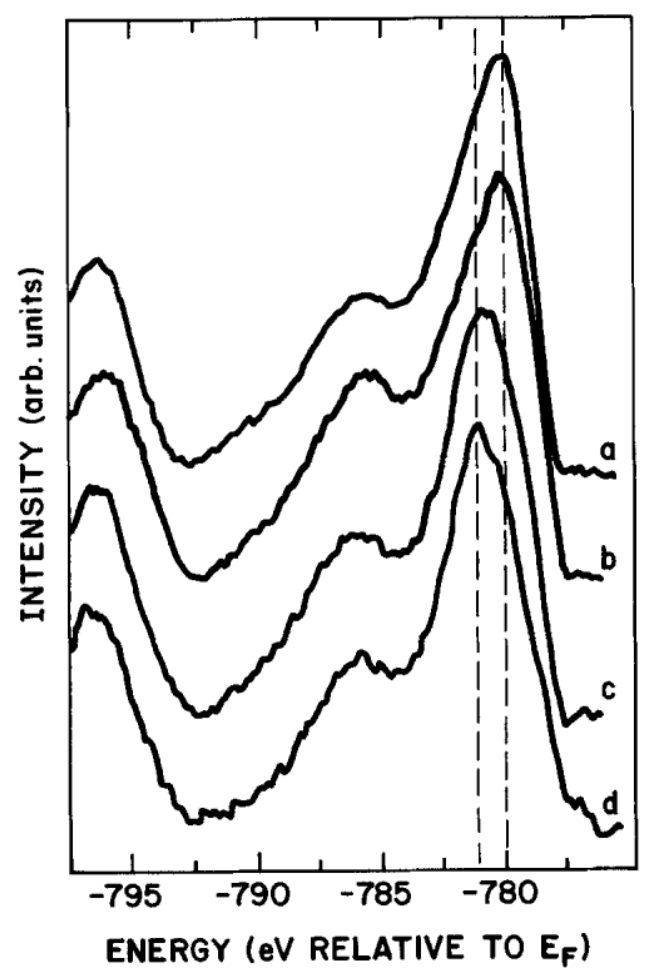

Fig. 4 Co 2p XPS spectra for the surface films on Co exposed to a, water; b, boric acid/borate buffer; c, water with BTA, and d, borate buffer with BTA.

These two curves show a slight shift of the main peak, with no change in position of the satellite peak. These spectra are typical of $\mathrm{Co}(\mathrm{OH})_{2} \cdot{ }^{5}$ The film thickness for the samples $\mathrm{c}$ and $\mathrm{d}$ is in both cases about $2.5 \mathrm{~nm}$. The results indicate that BTA plays a more important role in the formation of the surface film than whether the supporting electrolyte is water or borate. The observed differences in the corrosion rates, with the higher currents observed in water, could be explained by the weaker interaction of BTA with the Co surface showing $\mathrm{Co}^{+3}$, i.e., $\mathrm{CoO}(\mathrm{OH})$.

Effect of $\mathrm{Cu}^{+2}$ concentration.-As predicted, the initial corrosion rate of Co (measured 1 min after immersion) in a $10^{-3} \mathrm{M} \mathrm{CuSO}_{4}$ solution is higher than that in water even in the presence of BTA. This initial rate of Co dissolution decreases as the $\mathrm{Cu}^{+2}$ concentration decreases. The growth of the protective film on Co in $10^{-2} M \mathrm{BTA}+10^{-4} M \mathrm{CuSO}_{4}$ is illustrated in Fig. 5. The growth of the new film is clearly associated with the addition of cupric ions and seems to be parabolic in nature. If we assume that the entire change in ellipsometric parameter $\Delta$ is caused by the new film and not roughening, the thickness of this film measured in situ is about $12 \mathrm{~nm}$ (calculated with the refraction index of 1.5 for CuBTA). Films formed with more dilute $\mathrm{CuSO}_{4}$ had lower thickness both in situ and especially after rinsing and drying. 


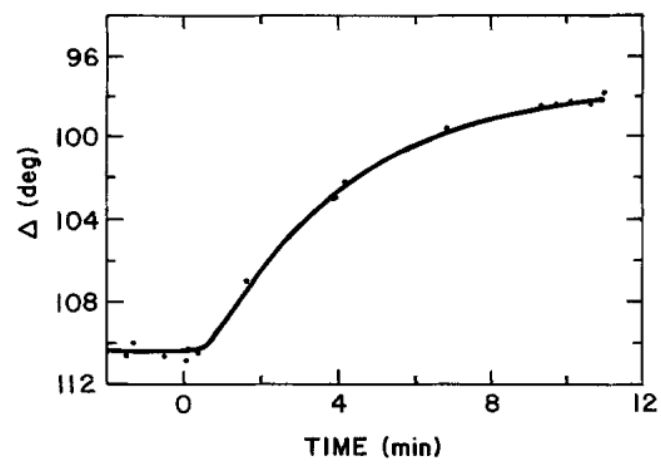

Fig. 5 Change of $\mathrm{A}$ with the addition of $10^{-4} \mathrm{M} \mathrm{CuSO}_{4} \times 5 \mathrm{H}_{2} \mathrm{O}$ added to deionized water containing $10^{-2} \mathrm{M}$ BTA.

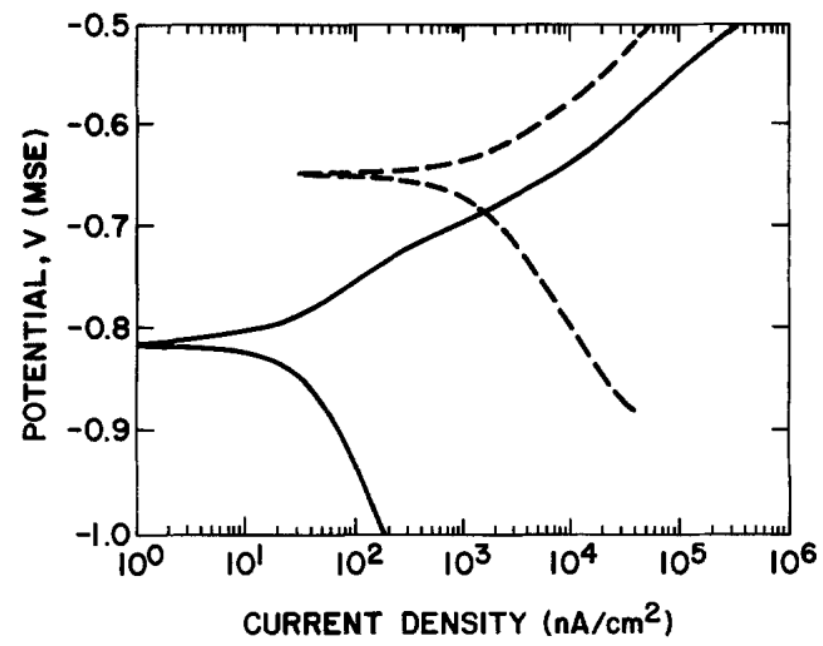

Fig. 6 Potentiodynamic polarization curves obtained on Co in water with (solid curve) or without (dashed curve) prior exposure to an aqueous solution containing $10^{-2} M$ BTA and $10^{-4} M \mathrm{CuSO}_{4} \times 5 \mathrm{H}_{2} \mathrm{O}$.

The typical surface film was about $3 \mathrm{~nm}$ thick after rinsing and drying. Films formed with dilute $\mathrm{CuSO}_{4}$ offer effective protection without a very high corrosion rate of $\mathrm{Co}$ at any time. The treated samples exhibit measurable permanent protection against corrosion in water, as illustrated in Fig. 6. The potentiodynamic curves in the figure were obtained on Co films in water, with and without prior exposure to a solution of $10^{-4} M$ of $\mathrm{CuSO}_{4} 5 \mathrm{H}_{2} \mathrm{O}+10^{-2} M$ BTA. Both the corrosion potential and the corrosion rate for the treated sample are significantly lower than those obtained for the untreated Co film. The data indicate that the decrease of the overall corrosion rate results from a preferential decrease in the rate of the cathodic reactions. This would not be the case if metallic $\mathrm{Cu}$ was deposited on the surface during the treatment.

Is there $\mathrm{Cu}$-BTA on cobalt?.-XPS analysis of Co samples prepared with different $\mathrm{Cu}-$ concentrations indicates that the protective film on Co does not contain elemental $\mathrm{Cu}$, Fig. 7. The kinetic energy peak at $918 \mathrm{eV}$ associated with the LVV Auger transition for metallic $\mathrm{Cu}^{6}$ is not 
present in the spectra. Samples treated with $\mathrm{CuSO}_{4} / \mathrm{BTA}$ in a glove box attached to the XPS chamber under Ar formed a film of $\mathrm{Cu}(\mathrm{I}) \mathrm{BTA}$ (7) (upper curve of Fig. 7). Upon exposure to air, however, $\mathrm{Cu}(\mathrm{I}) \mathrm{BTA}$ is readily oxidized to $\mathrm{Cu}(\mathrm{II}) \mathrm{BTA}$ (lower curve). This explains why the sample treated in air and then analyzed shows a mixture of $\mathrm{Cu}$ (I)BTA and $\mathrm{Cu}$ (II)BTA (middle curve). Such easy oxidation is not observed with the $\mathrm{Cu}(\mathrm{I}) \mathrm{BTA}$ formed on $\mathrm{Cu}$, but many electrochemical measurements have indicated that both $\mathrm{Cu}(\mathrm{I}) \mathrm{BTA}$ and $\mathrm{Cu}(\mathrm{II}) \mathrm{BTA}$ are protective.

Optimal application of $\mathrm{Cu}$-BTA film on Co.-The corrosion rate of $\mathrm{Co}$ in water with $10^{-}$ ${ }^{2} M$ BTA $+10^{-5} \mathrm{M} \mathrm{CuSO}_{4}$ is lower than that in water by 2 times during the first minute and by about 10 times after $5 \mathrm{~min}$. If the $\mathrm{pH}$ of the $\mathrm{BTA}+10^{-5} \mathrm{M} \mathrm{CuSO}_{4}$ solution is increased slightly by the addition of borate or ammonia, the corrosion rate of Co during treatment is very quickly reduced by about 1000 times compared to that in water. This is similar to the interaction of Co and BTA without $\mathrm{CuSO}_{4}$. The effect is apparently due to the protectiveness of BTA alone in alkaline solutions and the formation of CuBTA. The film formed in BTA + borate $+\mathrm{CuSO}_{4}$ offers an additional benefit. After the Co sample is removed from the solution containing BTA, rinsed, dried and then exposed to water, the rate of corrosion remains 10-50 times lower than measured on $\mathrm{Co}$ without prior exposure to the $\mathrm{BTA} / \mathrm{CuSO}_{4}$ solution, as shown in Fig. 8.

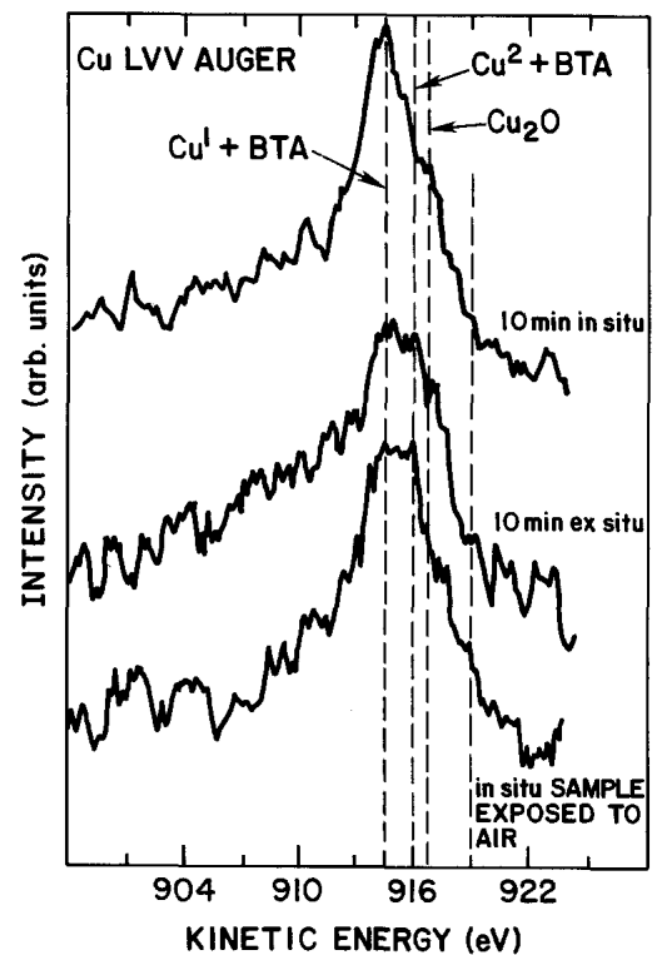

Fig. 7 XPS spectra for Cu LVV Auger transitions from Co samples treated with an aqueous solution containing $10^{-2} \mathrm{BTA}$ and $10^{-4} \mathrm{MCuSO}_{4}$ (i) in situ, i.e., in Ar glove box attached to the XPS system (upper curve) (ii) ex situ, i.e., in air and then analyzed (middle curve), ana (Hi), in situ, but exposed to air before the analysis. Kinetic energy for $\mathrm{Cu}^{0}$ is $\simeq 918 \mathrm{eV}$. 


\section{Conclusions}

Benzotriazole is an effective inhibitor for Co corrosion in aqueous solutions. In water, BTA reduces Co corrosion by a factor of $\simeq 10$ times but at $\mathrm{pH}$ levels $8-9$ this factor becomes close to 1000 times. Once the cobalt is removed from the inhibitor containing solutions, the surface retains only a marginal corrosion protection.

The corrosion resistance of $\mathrm{Co}$ can be further improved by the formation of a thin $\mathrm{Cu}$ BTA film on its surface. The best protection is achieved by immersion of Co in an aqueous solution containing $10^{-2} \mathrm{BTA}+10^{-5} \mathrm{MCuSO}_{4}+$ borate that is in itself not aggressive. This results in a surface film that retains protectiveness upon subsequent exposure to an environment that contains no inhibitor.

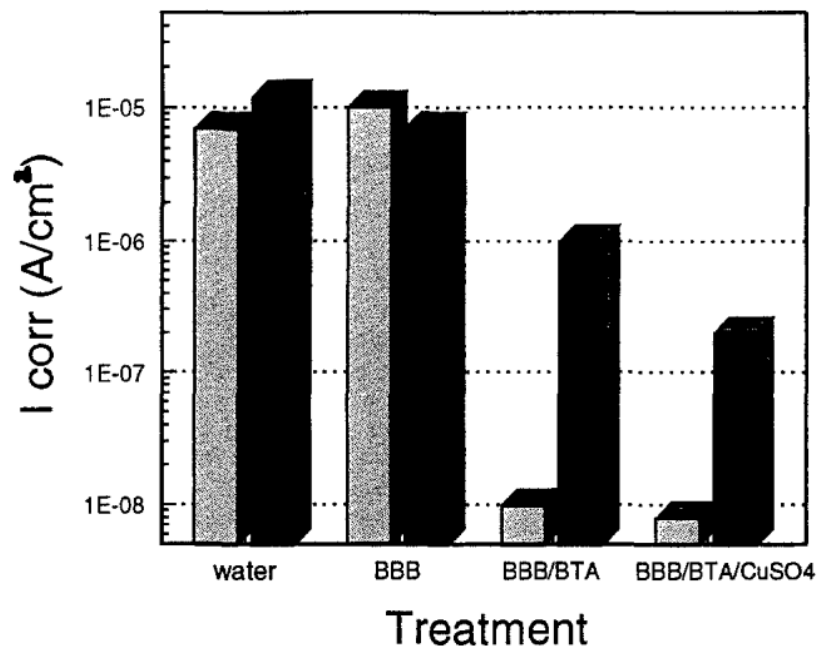

Fig. 8 Effects of BTA and cupric ions on Co corrosion in the borate buffer. Light bars, measured in electrolytes as noted; dark bars, measured in water after treatment in a solution with inhibitors (as noted).

Manuscript received Feb. 5, 1993. This was Paper 193 presented at the Toronto, ON, Canada, Meeting of the Society, Oct. 11-16, 1992.

IBM Research Division T.J. Watson Research Center, assisted in meeting the publication costs of this article.

\section{REFERENCES}

1. Proctor and Gamble, Ltd., Brit. Pat. 652, 339 (Dec. 1947).

2. V. Brusic, M. A. Frisch, B. N. Eldridge, F. P. Novak, F. B. Kaufman, B. M. Rush, and G. S. Frankel, This Journal, 138, 2253 (1991).

3. V. Brusic, M. Russak, R. Schad, G. S. Frankel, A. Selius, D. Dimilia, and D. Edmonson, ibid., 136, 42 (1989).

4. E. Mattsson and J. O'M. Bockris, Trans. Faraday Soc, 55, 1568 (1959).

5. N. S. Mclntyre and M. G. Cook, Anal. Chem., 47, 2208 (1975).

6. N. S. Mclntyre, S. Sundo, D. W. Shoesmith, and F. W. Stauchell, J. Vac. Sci. Technol., 18, 714 (1981).

7. S. L. Cohen, V. A. Brusic, F. B. Kaufman, G. S. Frankel, S. Motakef, and B. Rush, J. Vac. Sci. Technol, A 8, $2417(1990)$. 